\title{
Adults with chronic low back pain felt frustrated, unsupported, and powerless with healthcare, social, and legal systems
}

Walker J, Holloway I, Sofaer B. In the system: the lived experience of chronic back pain from the perspectives of those seeking help from pain clinics. Pain 1999 Apr;80:621-8.

QUESTION: What are the experiences of adults with chronic, benign, low back pain as they seek help and support from healthcare, social, and legal systems?

\section{Design}

Phenomenology.

\section{Setting}

2 pain clinics in southern UK.

\section{Patients}

20 consecutive adults (age range $28-80$ y, $60 \%$ men, duration of low back pain 2-50 y) with chronic, benign, low back pain who had recently started to come to the pain clinic.

\section{Methods}

Adults were interviewed for 1.5-3 hours in their homes by 1 of 2 investigators. The adults were asked to tell their stories (lived experiences) from inception of the pain. Probing, non-directive questions were used to elicit their feelings and thoughts about experiences and situations related to their pain. Issues related to healthcare, social, and legal services were explored if they emerged spontaneously. Audio tapes were transcribed and themes were developed, which were then validated by another researcher.

\section{Main findings}

5 sequential themes were identified: the pain takes over, sense of loss, in the system, they don't understand, and coming to terms. Adults felt that their lives had been irrevocably changed because of the pain and had a profound sense of loss that pervaded all aspects of their daily lives. They felt trapped within various systems and felt misunderstood and stigmatised, especially when obvious pathology to confirm their suffering was absent. These experiences made it difficult to come to terms with their situation.

Being in the system assumed a central part of the adults' lives. Initially, all received prolonged periods of bed rest with drugs and other treatments. The next step in the process included long periods of waiting for referrals, investigations and their results, appointments, surgery, and pain clinics. Feelings of frustration alternating with hope were common. None of the participants was satisfied with the medical process. Communication was poor and little coordination or continuity of care occurred. Participants wanted to know why they had pain and why treatments did not appear to be effective. The expectations of identifying the causes of the back pain and implementation of effective treatments were not met, and the adults lost faith in the ability and interest of their caregivers. Participants also feared that the pain was "in their minds." Most participants lost their jobs and had to fight to make a legitimate claim for benefits and compensation that was recognised by the system. During the whole process, participants felt frustrated in that they were rendered passive, powerless, and trapped. Participants became frustrated by systems that were designed originally to provide help and protection.

\section{Conclusion}

During the process of seeking diagnosis and treatment, adults with chronic, benign, low back pain experienced frustration and felt that they were rendered passive, powerless, and entrapped by healthcare, social, and legal systems that were initially designed to provide help and protection.

\section{COMMENTARY}

The study by Walker $e t a l$, although restricted to the experiences of patients with back pain, provides a valuable contribution to qualitative research in the area of chronic pain. The participants in the study provided a rich narrative of their pain history and their interactions with health professionals, lawyers, and benefit agency employees.

Similar to previous research, ${ }^{1}$ this study highlights the effect of chronic pain on an individual's economic and psychosocial wellbeing. To clinicians working in the field of pain management, some of the issues raised by the patients are not new; this, however, is the first qualitative study to go beyond the level of anecdote. Referrals from one hospital specialist to another, stigmatisation of back pain, litigation, seeking a diagnosis or cure, and referral to the pain clinic as the last resort are not new concepts. Comparative studies looking at other pain clinic patients might be useful to enable health professionals to determine whether the experience is familiar and the negative perceptions of care are common.

Health professionals have to question whether the medicalisation of chronic back pain ${ }^{2}$ continues to impair the implementation of effective approaches to managing pain and rehabilitation. Nurses should acknowledge the need to maintain effective communication with patients and the importance of partnership with patients if realistic and achievable pain management goals are to be met.

This study reinforces the concept of a multidisciplinary approach to managing chronic pain and should encourage those working in pain clinics to review and critique their practice.

Patricia Lane RN, MSc Clinical Nurse Specialist, Pain Management Barnet Hospital Barnet $\mathcal{E}^{\circ}$ Chase Farm NHS Trust Barnet, Hertfordshire, UK

1 Bowman JM. Reactions to chronic low back pain. Issues Ment Health Nurs 1994;15:445-53.

2 Radley A. Making sense of illness. London: Sage Publications, 1994 